\title{
Case Study: Use of MOODLE to Improve Teaching Learning Process in Control System Engineering
}

\author{
Lekha Das $^{1}$, Megha Sharma ${ }^{2}$ \\ ${ }_{1,2}$ Department of Electronics Engineering, K J Somaiya College of Engineering, Mumbai, India \\ ${ }^{1}$ lekhadas@somaiya.edu \\ ${ }^{2}$ meghasharma@somaiya.edu
}

\begin{abstract}
MOODLE based classroom is implemented to improve teaching learning process. Some content of curriculum was covered using flip classroom technique which includes out-class and in-class activity (using active learning strategies). Attainment of course outcomes of each course contribute to the programme outcomes. Results of two consecutive years are compared and the results show that there is significant improvement in the Course outcomes of the course for these two consecutive years. It was experienced in academic year 2016-17 students' finds difficult to understand concept of time domain and frequency domain analysis. Different teaching methodologies have been incorporated in the academic year 2017-18 to make these topics understandable.
\end{abstract}

Keywords: Flip Class Room (FCR), Active Learning, Course Outcomes, MOODLE (Modular ObjectOriented Dynamic Learning Environment), Think Pair Share, Team Pair Solo

\section{Introduction}

Conventional teaching is more teacher-centred activity. In this learners may be passive listeners.

\section{Lekha Das}

Department of Electronics Engineering, K J Somaiya College of Engineering, Mumbai, India lekhadas@somaiya.edu
Another knowledge sharing system is Information and Communication Technologies (ICTs) based system [1]. Technology based learning system emerged from the use of ICTs (e-learning) made the contents available to learners in a distant place through communication networks. ICT can be used in parallel with a class room teaching. MOODLE (Modular Object-Oriented Dynamic Learning Environment) is a platform for education which provides custom learning environment for students Moodle is a web-based Learning Management System (LMS) [2]. Documents can be shared and accessed in an arranged order. Online assignments save time and make submission procedure simple.

This paper explains how to use moodle and its effect on the teaching learning process. This methodology was implemented for teaching the fundamental course in Control System Engineering for second year engineering students. Seventy students were enrolled for the course . Open source platform named "gnomio" was used as moodle. This work is licensed under the Creative Commons Attribution-ShareAlike 4.0 International License which enables the user to use, distribute and modify it, including for commercial purposes, provided acknowledge the source and Share-alike. Flipped class room (FCR) was introduced to the learners. FCR includes out class activities and in class activities depending on the difficulty level of the contents of the course. 


\section{Motivation}

The most important technical skill of an engineer is the ability to design a system, component, or process to meet desired needs. In control systems the formulation of control problems and the determination of control algorithms are based on the exact and precise knowledge of the deterministic control plant [3]. This knowledge is usually presented in the form of mathematical models. It was realised that the mathematical simulation of experiments would give students opportunity to solve control problems and integrate theoretical knowledge obtained at lectures with practical experience, where the role and relevance of each concept become evident. So simulations were performed as outclass activity.

\section{Methodology}

Control System Engineering is an application oriented and analytical approach based course [3]. This can be organised better using moodle. Learners can learn at their pace and understanding level. Teachers are more like facilitators. It is observed that attainment of course outcomes (CO2 and $\mathrm{CO} 3)$ were less against target attainment during 2016-17. Moodle class room approach was attempted first time for conducting the course. Before starting with moodle class, a video on "how to enrol and use moodle" was shared with students.

\section{A. Uploading and Enrolling learners}

Moodle(lekhadas.gnomio.com) was created with teachers' names who have editing rights, course prerequisite and course outcome displayed on dashboard. Bulk users were uploaded using csv file. Provision of self- enrolment was also available.

\section{B. Announcements}

Announcements of uploading of learning materials, Question Bank, Quizzes, MCQs, submission of assignment and many more were periodically done.

\section{Learning materials}

Learning materials like link for web sources, solved example problems, question bank and video lectures which were uploaded on the classroom helped the learners to learn at their pace.

\section{Flipped class room}

Flipped class room (FCR) methodology was incorporated. FCR is a blended learning strategy where the content delivery happens outside the class room. More active learning techniques are used inside class room. Own screencast-O-matic Videos were uploaded on moodle. Students were requested to watch the video on root locus and attempt quiz and simulation examples as outclass activity. During classroom teaching, Think-Pair-Share strategy was implemented as an in class activity. Learners were asked to perform a task. Prescribed time was given to think about the solution by own. They were asked to discuss in a pair to get a more accurate solution to the problem. All the ideas were shared to the teacher and an interactive discussion to obtain a perfect solution

\section{E. Team Pair Solo}

Experiments were discussed in the laboratory to a batch of 20 students. Pair of students performs the experiment. Analysis of result and conclusion need to be done individually. Experiments were designed to understand the concepts of time response, stability of higher order systems, simulation of root locus, speed control of D C motor etc. Videos of experiments were uploaded on moodle enabling the students to view it after laboratory hours.

\section{F. Peer Assessment}

Assignments were uploaded by students. Students were introduced to peer assessment. Evaluation weightage was not given for peer assessment but students were guided to follow the rubrics provided by teachers.It gave an access to other's solution and their a p proachinsolvingtheproblem.

\section{G. Discussion Forum and Feedback}

Learners were encouraged to put their queries on discussion forum while learning. This helped them to have peer interaction as well as availability of faculty outside college hours. Feedback was also taken on moodle to ensure their leaning and improve curriculum and teaching methods.

Some snapshots of moodle are reproduced here for reference. 
Welcome to my class on Control System Engineering

$+P_{\text {Announcernents }}$

+ to syllabus

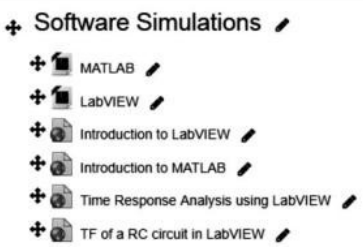

Fig. 1 : Announcements and software solutions

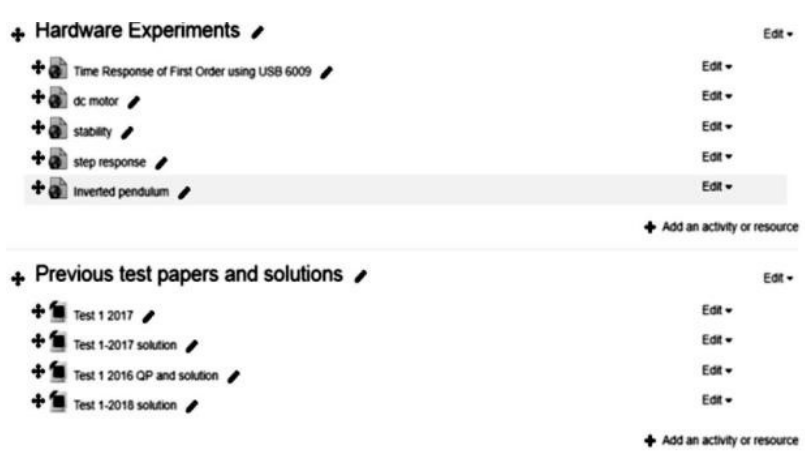

Fig.2 : Learning Material

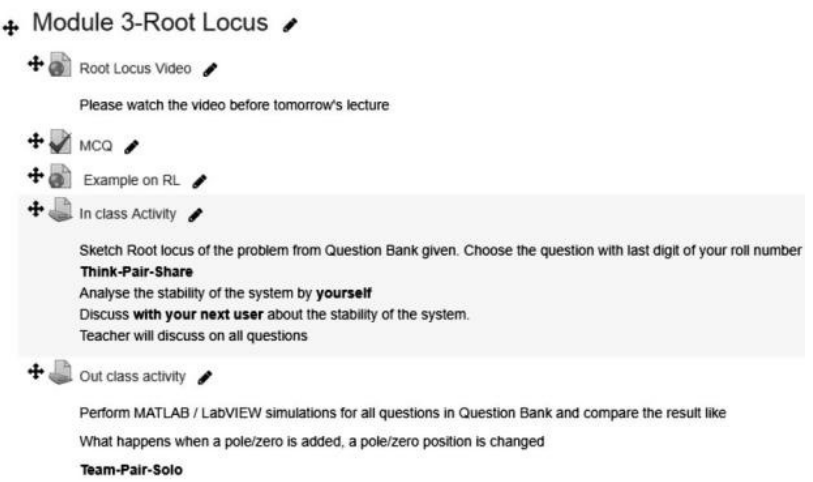

Fig.3 : Flipped Class Room
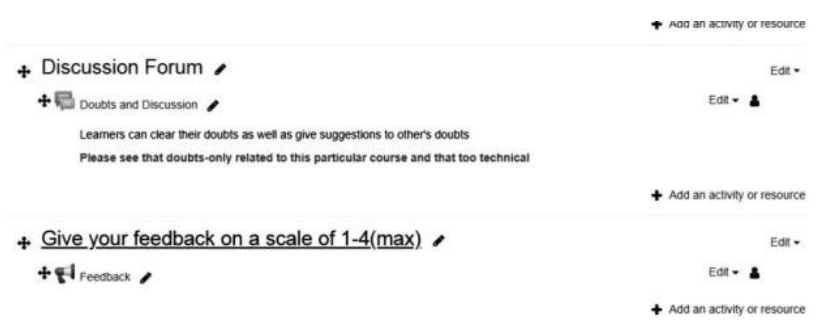

Fig.4 : Discussion Forum and Feedback

\section{Implementation}

Moodle class room was implemented for seventy students of second year Electronics Engineering in curriculum of a self-financed autonomous institute affiliated to University of Mumbai, India. Results shown are for students of 2016-17 and 2017-18. Since target set for Course Outcomes (COs) were not attained during 16-17, special efforts were taken during 2017-18

Table 1 : Course Outcomes

\begin{tabular}{|c||l||}
\hline $\begin{array}{l}\text { Course } \\
\text { Outcome }\end{array}$ & $\begin{array}{l}\text { After successful completion of the } \\
\text { course students should be able to }\end{array}$ \\
\hline $\mathrm{CO} 1$ & $\begin{array}{l}\text { Derive simplified mathematical model } \\
\text { of systems in different domains } \\
\text { (electrical, mechanical systems) by } \\
\text { applying first principles. }\end{array}$ \\
\hline $\mathrm{CO} 2$ & $\begin{array}{l}\text { Measure and improve performance } \\
\text { parameters of the systems in time } \\
\text { domain using classical control } \\
\text { techniques. }\end{array}$ \\
\hline $\mathrm{CO} 3$ & $\begin{array}{l}\text { Measure and improve performance } \\
\text { parameters of the systems in frequency } \\
\text { domain using classical control } \\
\text { techniques. }\end{array}$ \\
\hline $\mathrm{CO} 4$ & $\begin{array}{l}\text { Apply modern control techniques to } \\
\text { obtain performance parameters of } \\
\text { nonlinear control systems. }\end{array}$ \\
\hline
\end{tabular}

Short video lectures of 10-12 minutes duration were uploaded on moodle. It covered complete contents of the course. After watching videos learners were requested to attempt quizzes, solve problems from question bank. Simulations using scilab, MATLAB and LabVIEW enabled them to have the feel of performing experiments outside class room. As these soft-wares were introduced for first time, introductory presentations along with relevant videos were included in moodle. Simulations examples were uploaded on moodle so as to make students comfortable in performing simulations. Using these simulations, students could analyse the effect damping ratio on time response of a second order system, polezero position on system stability etc.

In this curriculum, tutorials were introduced to support teaching with problem solving. Though demonstration/experiments were done in the laboratory within the stipulated time of tutorials, it was not sufficient for the students to learn the concepts. Lack of laboratory session was a lacuna. 
This was tried to overcome by having the videos of experiments on moodle.

Experiments were on

1. Time response of first order system using DAQ card

2. Time response of second order system

3. Stability Analysis.

4. Inverted pendulum

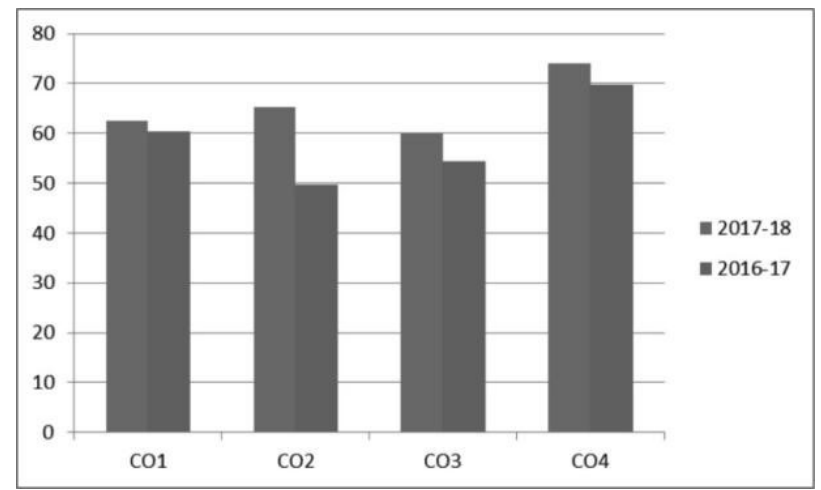

Fig.5 : Comparison of $\mathrm{CO}$ attainment

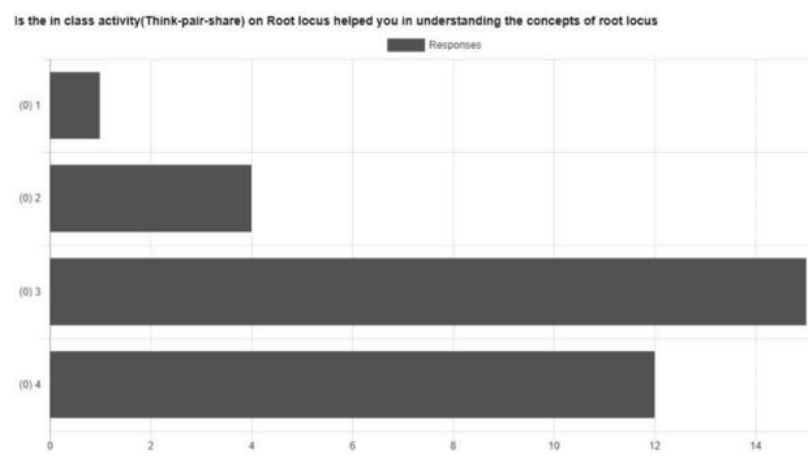

Fig.6 :Feedback Taken on MOODLE for in class activity through active learning methodology that helped them to design and analysis of control systems?

\section{A. Data gathered}

The following data was gathered for analysis at the completion of the study.

- The marks obtained by students of CSE during 2016-17 and 2017-18 which includes :

o End semester examination marks o

Continuous assessment

o Tutorials

- CO assessment of CSE in 2016-17 and 2017-18

- Student responses to the survey questions.

\section{Results}

In the year 2016-17 attainment level of $\mathrm{CO} 2$ and CO3 was not up to the target which was set at $60 \%$. Target is set at $60 \%$ with the understanding that every learner should be gaining at least $60 \%$ marks to have attained the course outcome.

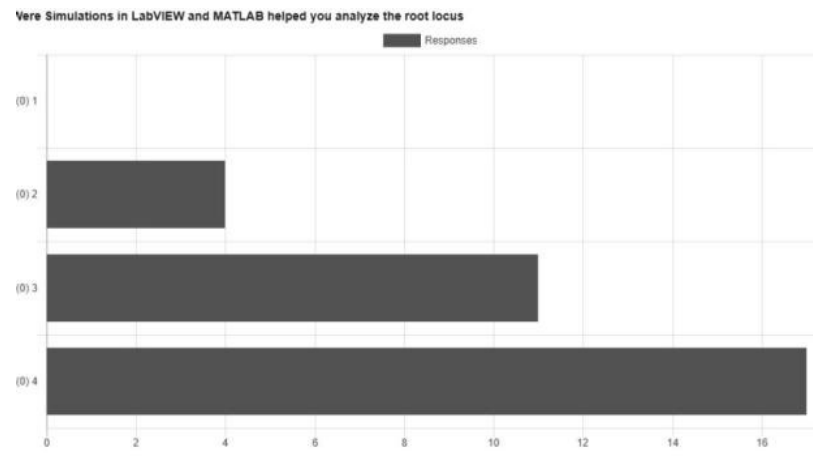

Fig.7 : Feedback Taken on MOODLE for out class activity

It is observed after implementing moodle it has improved and efforts were successful.

This is shown in the comparison of result of these two consecutive years.

Pedagogy used to improve $\mathrm{CO}$ attainment is Flip activity is shown in Fig.6. and Fig.7.

Through this study we try to find answer to the following research questions Class Room. Feedback for in class and outclass 
RQ1: Whether students learnt better in time domain analysis to fulfil the course outcomes?

From the evaluation of continuous and end semester assessment it is observed that learning experience is better. Hardware experiments, simulations and problem solving in tutorials enriched students with the concept of time domain analysis. This is shown in the $\mathrm{CO} 2$ attainment.

RQ2: Whether students perceived knowledge through active learning methodology that helped them to design and analysis of control systems?

From the feedback received students feel that pedagogy used helped them to design and analyse control systems. Attainment of COs ensures that active learning methods really helped them to learn the course in a better way. Students could use the class at their convenience and pace.

\section{Future Scope}

As technology is now in the palms of learners this can be converted into mobile application. This will enable learners to apply in real classroom itself. Peer review can be included for more ideas on active learning

\section{References}

[1]K. Sheo, G.Anil, D. Kamlesh , "A comparative study of MOODLE with other e-Learning systems", IEEE 2011, Pg No. 414-418.

[2]A.Ajlan, Z. Hussain , "Why Moodle" 12th IEEE International workshop on future trends of Distributed Computing systems

[3]S. Megha, P. Aarti , "A Case Study : Improvement in attainment of course outcomes of Control system engineering.”, ICTIEE 2017

[4]M. Sunita , S. Trupti "Open Educational Resource (OER): C-Programming Handout based Lab Session using MOODLE for Engineering Education", Journal of Engineering Education Transformations, Volume, No, Month 2015, ISSN 2349-2473, eISSN 2394-1707 